\section{Chromium Ribonucleoprotein from Bovine Liver}

WE have recently isolated from beef liver a ribo. nucleoprotein containing $0 \cdot 1$ per cent of chromium.

Chromium $(Z=24)$, manganese $(Z=25)$ and nickel $(Z=28)$ are the only metals of atomic numbers be tween 23 (vanadium) and 30 (zinc) which have not been shown to exhibit biological functions in associa tion with specific organic substances in vivo. The atomic structure and chemical reactivities of these three elements, however, have many similarities to those of vanadium $(Z=23)$, iron $(Z=26)$, cobalt $(Z=27)$, copper $(Z=29)$, and zine $(Z=30)$, the elements of the first transition group of the periodic table known to have distinct biological activities in conjunction with specific biological products. The abundance of manganese and chromium in the biosphere actually exceeds that of all these, except iron. Such circumstances have led to the conjecture that these elements would yet be detected in discrete biological compounds with specific biological roles ${ }^{1}$.

On this basis we sought to identify an organometallic substance containing chromium. A first suggestion that such a complex exists arose from the discovery that one of the intermediate fractions in the isolation of beef liver glutamic dehydrogenase, the precipitate obtained after the addition of 28 per cent sodium sulphate, reproducibly contained substantial aggregations of chromium varying from 22 to $40 \mu \mathrm{gm}$./ gm. dry weight, nearly one thousand fold enrichment of this metal over its concentration in beef liver, $0.05 \mu \mathrm{gm}$. $/ \mathrm{gm}$. dry weight ${ }^{2,3}$.

In the further isolation of this chromium-containing substance the procedure employed for the isolation of beef liver glutamic dehydrogenase was followed ${ }^{4}$. However, after the second precipitation at $p \mathrm{H} 5 \cdot 8$, the resulting precipitate was dissolved in $0.05 M$ potass. ium phosphate, $p H \mathbf{H} 7 \cdot 4$ and instead of sodium sulphate, ammonium sulphate was added in stepwise fashion, in increments of 10 up to 90 per cent saturation. After each addition, the precipitated material was removed by centrifugation, and both the precipitates and the supernatant solutions were analysed for chromium. In each instance the major portion of the chromium remained in the supernatant fraction. The supernatant fraction, after the addition of ammonium sulphate to bring it to 90 per cent saturation, was dialysed against $0.05 M$ potassium phosphate buffer and lyophilized. The chromium contents of the various fractions are shown in Table 1. The final

\begin{tabular}{|c|c|c|c|}
\hline \multicolumn{4}{|c|}{$\begin{array}{l}\text { Table 1. CHROMIUM CONTENT OF FRACTIONS OBTAINED IN } \\
\text { ISOration OF A RIBONUCLEOPROTEIN FROM BEEF LIVER } \\
\text { Chromium in } \mu \mathrm{gm} \text {. } / \mathrm{gm} \text {. dry weight }\end{array}$} \\
\hline Mainline Fractions & & Discard Fractions & \\
\hline Whole liver & 0.05 & Precipitate $A$ & \\
\hline Homogenate & & nt $B$ & \\
\hline $\begin{array}{l}\text { Supernatant } A \\
(20 \% \text { ethanol })\end{array}$ & & Supernatant $C$ & \\
\hline Precipitate $B$ & $7 \cdot 9$ & $\begin{array}{l}50 \% \text { Ammonium sulphate } \\
\text { precipitate }\end{array}$ & \\
\hline $\begin{array}{l}\text { Precipitate } C \text { ( } 5 \% \text { ethanol, } \\
p \mathbf{H} 5 \cdot 8)\end{array}$ & $12 \cdot 0$ & $\begin{array}{l}90 \% \text { Anmonium sulphate } \\
\text { precipitate }\end{array}$ & \\
\hline
\end{tabular}

$50 \%$ Ammonium sulphate $240 \cdot 0$

supernatant

$\%$ Ammonium sulphate $1080 \cdot 0$

material contained $1080 \mu \mathrm{gm}$. of chromium per gm. dry weight, a 20,000-fold enrichment over the concentration of this metal in whole liver. The pronounced maximal absorption at $258 \mathrm{~m} \mu$ of the lyophilized material, dissolved in $0.05 M$ potassium phosphate, $p H$ 7.4, suggested the presence of a nucleic acid. The material was shown to be composed of 70 per cent ribonucleic acid, measured by the orcinol method ${ }^{6}, 30$ per cent protein ${ }^{6}$ and 4.0 per cent phosphorus? ${ }^{7}$ The substance did not react with diphenylamine, indicating that deoxyribonucleic acid was absent ${ }^{8}$. The lyophilized material was dissolved and dialyzed for $48 \mathrm{hr}$. against metal-free water. Chromium was not removed. While chromium is here singled out for discussion because of the unique nature of its occurrence, spectrographic analysis of this dialysed material demonstrated that in addition to chromium it also contained very substantial quantities of calcium, magnesium, strontium, barium, aluminium, iron, nickel and zine (Table 2).

\begin{tabular}{lccr}
\multicolumn{4}{c}{} \\
Metal Content in $\mu \mathrm{gm}$./gm. dry weight \\
PROTETR F \\
Magnesium & 7880 & Aluminium & 930 \\
Calcium & 13000 & Iron & 1540 \\
Strontium & 97 & Chromium & 1080 \\
Barium & 350 & Nickel & 2340 \\
& Zine & 4950 &
\end{tabular}

To our knowledge the demonstration of the association of chromium and nickel with this ribonucleoprotein represents the first instance in which these metals have been found to be associated firmly with a specific native biological product. These two metals, like the other members of the first transition group of the periodic table, may therefore perform unique biological functions in conjunction with specific biological compounds.

The occurrence of these and other metals in this location suggests that they play a part in the function of nucleic acids, either in the maintenance or their structure or to provide specific sites of binding between proteins and nucleic acids. Metals are known to serve in the maintenance of protein structure, apparently through their ability to form strong covalent bonds with organic ligands ${ }^{9-11}$; chromium, in fact, has been reported to be exceptional in its capacity to act as a 'cross-linking' intermediate between individual protein molecules, such as collagen and conarachin ${ }^{12,13}$. We have considered the possibility that some of these metals may stabilize acid structure through the formation of "sandwich complexes'14, while some may serve to link nucleic acids to protein.

The discovery of metals in this ribonucleoprotein has led to the examination of the metal content of nucleic acids from a wide variety of phyla and species, all of these contain large amounts of the same metals. The details of this work and its implications for the biological function of nucleic acids will be reported elsewhere.

This work was supported by the National Institutes of Health and Welfare Grant No. H3117 $(C)$ and the Howard Hughes Medical Institute.

W. E. C. WACKER B. L. VALLER

Biophysics Research Laboratory,

Department of Medicine,

Harvard Medical School and

Peter Bent Brigham Hospital, Boston, Massachusetts.

1 Vallee, 13. L., in Principles of Internal Medicine, third Ed., T. Harrison, Ed., 465 (Blackiston, Co., New York, 1957)

Adelstein, S. J., 'Glutamic Dehydrogenase, a Zinc Metalloenzyme' Thesis; Mass. Inst. Technology (1957).

Adelstein, S. J., and Vallee, B. L., J. Biol. Chem., 233, 589 (1958).

4 Olson, J. A., and Anfinsen, C. B., J. Biol. Chem., 202, 841 (1953)

Mejbaum, W. S., Z. Physiol. Chem., 258, 117 (1939)

Lowry, O. H., Rosenbrough, N. S., Farr, A. L., and Randall, R. J., J. Biol. Chem., 193, 265 (1951)

Fiske, G. H., and Subarrow, Y., J. Biol. Chem., 68, 375 (1925),

Seibert, F. B., J. Biol. Chem., 133, 593 (1940).

Stein, E. A., Fed. Proc., 16, 254 (1957).

Kaegi, J. H. R., Fed. Proc., 18, 484 (1959)

Frieden, C. J., Biochem. Biophys. Acta, 27, 431 (1958),

12 Gustavson, K. H., Nature, 182, 1125 (1958)

3 Naismith, W. E. F., Arch. Biochem. Biophys, 73, 255 (1958).

14 Kealy, T. S., and Palson, P. L., Nature, 168, 1039 (1951). 